\section{A TERRITORIALIZAÇÃO DE POLÍTICAS PÚBLICO-AMBIENTAIS NO RURAL PAULISTA: UM ESTUDO DE CASO ${ }^{1}$}

Mariana Bombo Perozzi Gameiro ${ }^{2}$ Rodrigo Constante Martins ${ }^{3}$

Resumo: Este artigo visa reconstituir as redes de poder envolvidas em uma das primeiras políticas públicas com enfoque territorial, decentralizado e participativo para o desenvolvimento rural do Estado de São Paulo. O Programa de Microbacias Hidrográficas I, financiado pelo Banco Mundial, foi desenhado na década de 1990 e executado pelo governo paulista através da Coordenadoria de Assistência Técnica Integral, entre 2000 e 2008. O objetivo do programa era melhorar as condições socioeconômicas e ambientais das regiões rurais, elegendo o nível das microbacias como base territorial para ação. Ao comparar a estrutura formal de funcionamento do projeto com as práticas, este artigo apresenta um contraponto ao entendimento institucional das políticas públicas para o meio rural, ressaltando a importância das análises da conjuntura de poder nos níveis macro e territorial. Os procedimentos metodológicos incluíram entrevistas semiestruturadas, análise documental e revisão de literatura. Os resultados revelam estruturas complexas onde os especialistas desempenham papel central face às instituições e comunidades locais.

Palavras-chave: Desenvolvimento Rural; Políticas Públicas; Banco Mundial.

\footnotetext{
Este trabalho contou com o apoio financeiro da FAPESP.

Doutora pelo Programa de Pós-Graduação em Sociologia da Universidade Federal de São Carlos (UFSCar) Pesquisadora do Grupo de Pesquisa CNPq Ruralidades, Ambiente e Sociedade (RURAS). E-mail:marianaperozzi@gmail.com
}

${ }^{3}$ Professor do Departamento de Sociologia e do Programa de Pós-Graduação em Sociologia da UFSCar. Coordenador do RURAS. E-mail: rmartins@ufscarbr
Abstract: This paper aims to reconstitute the power networks involved in one of the first public policies with a territorial, decentralized and participative approach for the sustainable rural development of Sao Paulo state (Brazil). Land Management III Project was financed by the World Bank, designed in the 1990's and executed from 2000 to 2008 by the State Secretariat of Agriculture. The project's objective was to improve environmental and socioeconomic conditions of rural regions, electing the microwatershed level as the territorial basis for action. By comparing the project's formal structure of functioning and its practices, this paper presents a counterpoint to institutional understandings of public policies for rural areas, highlighting the importance of power conjunctures analysis in macro and territorial levels. Methodological procedures included semi-structured interviews, document analyses and literature review. The results unveil complex structures where experts play a central role in face of institutions and local communities.

Keywords: Rural development; Public Policies; World Bank

\section{Introdução}

Até os anos 1980, aproximadamente, as políticas de desenvolvimento rural costumavam focar nos investimentos em infraestrutura e no aumento da produção agrícola. Contudo, durante aquela década, ênfase começou a ser dada para os capitais humanos e culturais das localidades, numa abordagem que procura desenvolver o potencial dos atores locais. Estudos revelam, porém, que as estruturas sociopolíticas se tornam gradativamente mais complexas à medida que novos grupos sociais competem com interesses já estabelecidos para influir sobre as políticas rurais. A participação de grupos antes à margem do processo decisório implica no rearranjo das relações de poder, o que gera tensões e choques de interesses.

O objetivo deste artigo é analisar a formulação e implementação de políticas públicas para o que se convencionou chamar de "novo rural" brasileiro. Para tanto, toma-se como estudo de caso o Programa de Microbacias Hidrográficas do Estado de São Paulo (PEMH), política pública territorializada, descentralizada e participativa, com vistas ao desenvolvimento rural. Foi parcialmente financiada pelo Banco Mundial e executada pelo governo paulista através da Coordenadoria de Assistência 
Técnica Integral, entre 2000 e 2008.

Como procedimento metodológico, foram adotados procedimentos qualitativos de pesquisa social, incluindo levantamento bibliográfico, levantamento documental e entrevistas semi-estruturadas. As entrevistas foram realizadas no período de outubro de 2010 a julho de 2011, e envolveram técnicos executores do PEMH, diretores dos escritórios regionais da CATI (órgão de extensão rural do estado de São Paulo), o gerente de planejamento do PEMH e um representante do Banco Mundial, que coordena a área de desenvolvimento sustentável da instituição.

Do ponto de vista analítico, convém uma nota sobre as bases conceituais do estudo. Sustentamos que os modelos de desenvolvimento rural nascem no que Giddens (1991) chama de sistemas peritos. Estes são, por definição, os sistemas de excelência técnica ou competência profissional que organizam grandes áreas dos ambientes material e social em que vivemos, influenciando-nos de maneira contínua. Os sistemas peritos proporcionam o desencaixe das relações sociais, ou seja, seu deslocamento dos contextos locais de interação, com sua reestruturação através de extensões indefinidas de tempo e espaço. Assim, discursos peritos sobre a temática rural e sobre a necessidade de regulação ambiental influenciam políticas públicas e a legislação voltadas ao campo, afetando aspectos práticos da vida dos moradores das áreas rurais e a definição político-ideológica de identidades.

Para o autor, tanto leigos quanto especialistas têm consciência das fragilidades e limites dos sistemas peritos. Giddens (2002) afirma que poucos indivíduos mantêm uma confiança inabalável nos sistemas de conhecimento técnico que os afetam, e todos, consciente ou inconscientemente, escolhem entre as possibilidades concorrentes de ação que tais sistemas (ou o abandono deles) oferecem. A confiança, muitas vezes, se mistura à aceitação pragmática, de modo que atitudes de antagonismo ou ceticismo coexistem com crenças não-questionadas. Esta espécie de "fé" geralmente é depositada, pelos atores leigos, na autenticidade do conhecimento perito, não no indivíduo que o representa - um profissional que, por sua vez, é também leigo em outros campos que não o que ele atua.

Encontros com representantes de sistemas peritos podem, de qualquer modo, ser regularizados e facilmente assumir características de confiabilidade associada com amizade e intimidade (GIDDENS, 1991). Estes encontros presenciais, que Giddens chama de compromissos com rosto, tendem a ser dependentes da postura dos representantes ou operadores do sistema, de modo que se renove permanentemente a confiança - tanto na fidedignidade do indivíduo quanto no conhecimento ao qual o leigo não tem acesso.

\section{O novo rural e as políticas públicas}

A observação das transformações sociais, econômicas, culturais e também ambientais experimentadas no meio rural nas últimas décadas propiciou, nos anos 1980 e 1990, um movimento de discussão sobre quais seriam os modelos mais adequados para o desenvolvimento deste "novo rural" que emergia. O "novo rural" se caracterizava pela diluição de suas fronteiras com os espaços urbanos, uma conseqüência do processo de modernização da agricultura ocorrido em décadas anteriores ${ }^{4}$. Especialmente no interior paulista, as atividades agrícolas respondiam cada vez menos pela geração de empregos e renda no meio rural, enquanto as atividades não-agrícolas - tais como a prestação de serviços, o comércio e a indústria - ganhavam importância. Desta forma, o meio rural não poderia mais ser atrelado apenas à agropecuária (cultivos agrícolas e criação de animais), ganhando importância dimensões como moradia, lazer e preservação ambiental (GRAZIANO DA SILVA, 1998).

Em âmbito internacional, acadêmicos e pesquisadores também constatavam o crescente interrelacionamento do meio rural com a sociedade urbana, a sinergia entre atividades agrícolas e não-agrícolas, a emergência de novos atores nos espaços rurais (proprietários de sítios de lazer, de moradias secundárias, empresas de diversos ramos, etc), além das múltiplas facetas ambientais que envolviam o uso sustentável e o manejo adequado dos recursos naturais nestes espaços (VAN DER PLOEG et al, 2000).

Novas abordagens para o desenvolvimento rural, gestadas em espaços construtores do conhecimento perito, sugeriam, assim, que as políticas públicas voltadas ao desenvolvimento rural necessitavam deslocar o enfoque do produtor rural para as redes de atores, do setor agrícola para dinâmicas socioeconômicas variadas, das ações centralizadas para enfoques descentralizados, orientados "de baixo para cima". A implementação destes mecanismos se basearia no emprego de métodos participativos para engajar

${ }^{4}$ Graziano da Silva (1998) afirma ter ocorrido a urbanização de algumas áreas rurais brasileiras nos anos 1980 a intensificação do trabalho assalariado no campo e a tecnificação dos produtores familiares ligados aos complexos agroindustriais. O autor coordenou um projeto intitulado Rurbano - "Caracterização do Novo Rural plexos agroindustriais. O autor coordenou um projeto intitulado Rurbano - "Caracterização do Novo Rural
Brasileiro, 1981-1995", que analisa as transformações recentes no meio rural de onze unidades da federação, com foco nos dados das PNADs (Pesquisas Nacionais por Amostra de Domicílios), do IBGE. 
as populações rurais em processos de planejamento, consultas, etc; em parcerias entre agências governamentais, o setor privado e organizações civis na condução de projetos; no incentivo ao empreendedorismo e ao desenvolvimento de projetos encabeçados pela comunidade, com apoio financeiro do Estado (WOODS, 2009).

Este modelo de desenvolvimento com foco no território, diversidade e otimização de recursos e capitais locais foi adotado como base para a formulação de políticas públicas voltadas ao meio rural a partir dos anos 1990, ao redor de todo o mundo, contando ainda com o forte incentivo de instituições multilaterais de desenvolvimento. Gameiro (2010) analisou os principais documentos oficiais do Banco Mundial sobre desenvolvimento rural - notadamente relatórios com as propostas estratégicas de atuação da instituição -, publicados entre 1997 e 2008. Para a autora, o Banco aposta fortemente no conhecimento acumulado em seu quadro para traçar políticas e programas a serem implementados nos países tomadores de recursos. Suas propostas se retroalimentam e encontram legitimidade junto a diversos grupos de atores sociais, inseridos em sistemas peritos. A leitura dos documentos estudados revela, em termos gerais, que o Banco Mundial postulava a necessidade de um olhar ampliado sobre o rural e não restrito à agricultura, estimulava o envolvimento do público beneficiário na execução dos projetos e a promoção do uso sustentável dos recursos naturais, em linha com a produção acadêmica contemporânea (GAMEIRO, 2010).

A operacionalização de políticas públicas participativas e descentralizadas exige um ativo papel dos profissionais da extensão rural. Destes peritos se espera uma postura de articulador e catalisador de interesses, de modo a promover a mobilização de capitais - sobretudo sociais - que favoreçam o desenvolvimento das potencialidades locais.

Análises acerca do desempenho destas políticas revelam, por sua vez, seus inúmeros limites. Marsden e Murdoch (1998) falam que autoridades locais podem desempenhar o papel de grupo de pressão dentro das novas modalidades de governança; e destacam a falta de autonomia ou responsabilidade real da comunidade, que serviria apenas como conselheira ou consultora. Gehlen (2004) indica o fortalecimento dos agentes que apresentam racionalidade moderna e centrada na ética do trabalho e da competitividade, mantendo a desigualdade perante os portadores de racionalidades diferentes, como as centradas em valores de convívio. Martins (2005) revela as relações desiguais de poder escondidas na democracia formal presente na composição de conselhos e comitês rurais; e Abramovay (2000) destaca as frequentes práticas clientelistas, autoritárias e burocráticas que caracterizam tais estruturas descentralizadas de governança.

A despeito das persistentes limitações das abordagens participativas e descentralizadas do desenvolvimento rural, estes pressupostos mantêm, dentre os formuladores de políticas públicas e peritos em desenvolvimento, um status muito positivo, representativo de certo "avanço" no modo de conceber e operacionalizar projetos nesta área.

O governo paulista implementou, entre 2000 e 2008, um programa de "desenvolvimento rural sustentável" chamado Programa de Microbacias Hidrográficas do Estado de São Paulo (PEMH), financiado pelo Banco Mundial e executado pela Secretaria Estadual de Agricultura e Abastecimento (SAA), através da Coordenadoria de Assistência Técnica Integral (CATI). O PEMH é tido por Navarro (2008) como a primeira experiência de desenvolvimento rural que, de fato, houve no país, trazendo em sua concepção muitos dos aspectos preconizados pela literatura internacional e nacional da área.

\section{A formulação do PEMH}

Os sistemas peritos produzem conhecimento a respeito das dinâmicas rurais e reflexivamente colaboram para a construção do imaginário social sobre esses espaços e as sociabilidades que se desenrolam ali, influenciando também nos processos políticos, culturais e econômicos destas áreas. Como num ciclo, os peritos observam as transformações decorrentes destes processos - no caso em estudo, a observação de "novas" ruralidades -, reformulam suas teorias e, assim, atualizam o conhecimento disponível sobre esta temática, provocando novos efeitos sobre o mundo das práticas - tais qual a orientação de programas de desenvolvimento rural.

Cabe destacar, porém, que os sistemas peritos não colonizam o mundo da vida, subordinando as decisões pessoais às perícias técnicas. O indivíduo é, segundo Giddens (1989), portador da capacidade de agência, que o permite processar a experiência social e traçar estratégias para enfrentamento da vida, mesmo sob formas de coerção. Dentro dos limites da informação, incerteza e outras restrições (físicas, normativas ou político-econômicas) que existem, os atores sociais são detentores de conhecimento e capazes de intervir no fluxo de eventos sociais do seu entorno. Esta relação de forças torna os processos de desenvolvimento rural bastante complexos, e as fronteiras entre 
o que é interno ou externo à vida rural tornam-se crescentemente ambíguas.

Diversos discursos peritos somam-se à decisiva influência dos debates acadêmicos acerca do desenvolvimento rural para a concepção de políticas públicas - fato particularmente marcante no Brasil, uma vez que alguns dos mais destacados especialistas da área também ocuparam postos governamentais. Um destes discursos é o referente à microbacia hidrográfica, que vinha ganhando notoriedade como unidade operacional para intervenções com fins conservacionistas e ambientais, sendo indicada para este fim por grande parte dos trabalhos acadêmicos brasileiros, sobretudo a partir das décadas de 1970/1980. Estes trabalhos contavam com a participação das instituições de ensino e pesquisa nacionais, incentivadas pelo poder público e pelo intercâmbio com atores estrangeiros. Tais conhecimentos peritos, traduzidos em políticas públicas, resultaram em experiências como os programas de microbacias dos estados do Paraná e Santa Catarina, que contaram com o aporte financeiro do Banco Mundial e inspiraram a criação do Programa de Microbacias do Estado de São Paulo (PEMH).

A primeira versão do PEMH tinha foco na recuperação e conservação de recursos naturais (solo e água), e foi submetida à avaliação do Banco Mundial em 1992, com a finalidade de obter empréstimos para seu desenvolvimento. Este enfoque conservacionista-ambiental já sinalizava a construção de novas visões de mundo sobre o rural, as quais escapam da noção tradicional que restringe o rural ao agrícola. $\mathrm{O}$ acordo esbarrou na existência de dívidas por parte do Estado junto à União (WORLD BANK, 2009), impedindo sua assinatura. Com a rolagem das dívidas, o Estado passou a ter capacidade para endividamento e abriu-se novamente a possibilidade de negociação junto ao BIRD. O discurso sobre sustentabilidade também passa a influenciar a concepção do programa, nesta época.

Naquele momento [1997], uma coisa era prioritária: voltar a negociar o acordo de empréstimo. Só que aí, o mundo tinha mudado. Nessa época, o Banco Mundial e a gente mesmo [Cati] via que seria necessário um projeto que fosse muito mais amplo que simplesmente conservação de solo e água. Existiam outras questões que eram importantes e precisavam ser discutidas, apoiadas. $\mathrm{Na}$ verdade, o que a gente tinha já nessa época era a idéia que o projeto devia ser a semente, o embrião, do que começava a ser chamado “desenvolvimento sustentável". Por isso que a gente colocou como objetivo do programa promover o desenvolvimento rural sustentável.
[...] O conceito vem da Comissão Mundial de Meio Ambiente, das Nações Unidas, que tinha o Relatório Brundtland... e já tinha havido a Eco $92 \ldots$ Na verdade, era dentro da extensão rural que isso não estava sendo muito discutido, mas havia uma discussão fora. A influência era exatamente o que a gente via dessas questões, o que estava acontecendo no mundo. (Gerente de Planejamento do PEMH).

Esta declaração explica o alargamento do enfoque do programa de microbacias paulista e a inserção da noção de desenvolvimento sustentável no trabalho da CATI, de acordo com o engenheiro agrônomo que foi gerente de planejamento do PEMH desde o início da renegociação do programa com o Banco Mundial, em 1997, até o término do programa, em 2008, posteriormente ocupando o posto de coordenador da CATI (2009-2011). A declaração indica, também, um processo de ressignificação do rural a partir da introdução de elementos ambientais e sociais, não-setorializados, que sugerem dinâmicas complexas e conflitivas para o estabelecimento de novas categorias de interpretação e intervenção no mundo, como preludiado pelo debate sobre as "novas ruralidades".

O depoimento é revelador, ainda, da confiança da CATI na perícia que envolve as Nações Unidas e suas propostas para o chamado "desenvolvimento sustentável". Esta noção de desenvolvimento sustentável se baseia em três pilares básicos - equilíbrio ambiental, prosperidade econômica e justiça social - e constitui a matriz discursiva dominante que legitima ações nesta área: o Relatório Brundtland (MOREIRA, 2007). O discurso sobre desenvolvimento sustentável da ONU se apresentava coerente para a CATI em vários aspectos, inclusive porque correspondiam ao momento político ${ }^{5}$ que o Brasil vivenciava na época:

Para desenvolver um projeto desses, como a gente imaginava para o PEMH, existia uma premissa que era muito coincidente com as premissas que você encontra, por exemplo, no relatório lá da Comissão Mundial de Meio Ambiente. A questão da participação, da transparência... vários aspectos desses eram fundamentais. $\mathrm{Na}$ verdade são princípios democráticos. Então, era muito mais uma questão de introduzir na extensão rural, além da questão ambiental, valores democráticos, principalmente a descentralização, a participação e a transparência. (Gerente de Planejamento do PEMH).

No Brasil, o declínio das ditaduras militares acende a discussão acerca da redemocratização do país. Participação e descentralização surgem como estratégias - ao menos discursivas - para a construção democrática e conferem legitimidade a um complexo processo de reorganização política. 
O discurso da sustentabilidade se alinha não apenas aos novos modelos de desenvolvimento rural que vinham sendo discutidos no âmbito acadêmico e nas agências internacionais de cooperação e fomento. Se alinha também aos objetivos da atuação do Banco Mundial no Brasil. A Estratégia de Assistência da instituição ao país, publicada em 1997, tem como principais componentes: a) reformas estruturais para consolidar a estabilidade e impulsionar o crescimento dirigido pelo setor privado; b) alívio da pobreza, inclusive rural; c) expansão da infra-estrutura; d) promoção do desenvolvimento sustentável (WORLD BANK, 2009).

Com estas linhas definidas para o Brasil, e com as diretrizes já desenhadas para a atuação do Banco no setor rural ao redor do mundo ${ }^{6}$, a abertura para negociação do PEMH com o Banco Mundial era relativamente limitada, se restringindo à adaptação de um modelo para as condições locais. Uma engenheira agrônoma, diretora de uma EDR na época desta entrevista, acompanhou o desenvolvimento do Programa de Microbacias em todas as suas fases, sendo assistente de planejamento da mesma EDR quando do início do programa, em 2000. A entrevistada explica as etapas prévias à assinatura do acordo de empréstimo, que envolviam: a) aprovações burocráticas e legais por parte do governo federal, do governo do Estado e do Banco Mundial, frequentemente em contextos de desencaixe que estendem os sistemas sociais ao longo do tempo e do espaço; e b) as negociações de aspectos técnicos, operacionais e institucionais do Programa, majoritariamente desenroladas em encontros face-a-face.

Nestas ocasiões de co-presença, geralmente participam os representantes do Banco (tanto os locados em Washington e vindos em missão para São Paulo, como também os locados no escritório do Banco Mundial em Brasília), representantes da CATI/SAA e consultores externos. Nestes episódios, construídos em torno do conhecimento perito, os conflitos entre os diferentes atores e as assimétricas relações de poder ficam mais evidentes. Para Giddens (1989), poder é a capacidade de obter resultados; não tem caráter intrinsicamente opressivo e pressupõe estruturas de dominação invisíveis. Os encontros são sustentados por laços de confiança estabelecidos entre os indivíduos, através do monitoramento reflexivo da ação e do cenário, dentro de rotinas previsíveis e de códigos compartilhados de comportamento, sendo a racionalização a base para a avaliação da competência do outro. No caso das reuniões do PEMH, o compartilhamento de identidades proporcionado

$$
\overline{{ }^{6} \text { Ver Gameiro, } 2010 .}
$$

por elementos como nacionalidade ou proximidade lingüística parece facilitar a interação e predispor os atores à confiança, como na seguinte declaração, proferida por um membro da CATI em referência a uma gerente de projeto do Banco Mundial que trabalhava na coordenação do PEMH: "Era boa a negociação porque ela era brasileira [...], era super aberta", diz, comparando-a a um europeu do staff do Banco que, em posição equivalente, representava dificuldade muito maior.

A renegociação do PEMH ocorreu no ano de 1997, mas a assinatura do Acordo de Empréstimo entre o Governo do Estado e o Banco Mundial só se efetivou em 07 de dezembro de 1999. Conforme informações oficiais:

Para tanto, foi necessária uma reorganização do Programa, começando pela redefinição do seu objetivo, que passou a ser o de promover o desenvolvimento rural sustentável no Estado de São Paulo; entendendo-se por desenvolvimento rural a ampliação das oportunidades de ocupação, a melhoria dos níveis de renda, uma maior produtividade geral das unidades de produção, uma redução dos custos e uma reorientação técnico-agronômica. Tudo para propiciar o aumento do bem-estar das populações rurais, através da implantação de sistemas de produção agropecuária que viessem a garantir a sustentabilidade sócio-econômica e ambiental, com plena participação e envolvimento dos beneficiários e da sociedade civil organizada. (SÃO PAULO, 2010).

O PEMH previa desembolsos de US\$ 55 milhões por parte do Banco Mundial e US\$ 69,70 milhões por parte da Secretaria de Agricultura de São Paulo, com início programado para o ano de 2000. Os investimentos estavam inicialmente divididos em seis grandes módulos, chamados "componentes" na linguagem do programa, e se direcionavam ao: 1) desenvolvimento institucional e tecnológico (extensão rural, assistência técnica, aquisição de veículos, computadores e outros equipamentos para o trabalho dos técnicos da CATI); 2) pesquisa agrícola; 3) manejo e conservação de recursos naturais; 4) readequação de estradas rurais; 5) treinamento e capacitação (tanto de técnicos quanto de produtores rurais e suas famílias ${ }^{7}$ ); 6) administração e supervisão do projeto. Parte dos recursos seria destinada aos agricultores beneficiários sob a forma de subvenção a fundo perdido.

Cursos sobre aproveitamento de alimentos, artesanato, panificação, entre outros eram especialmente dirigidos às mulheres. Tais ações, porém, dependiam da demanda da comunidade local e da sensibilidade do técnico, que deveria identificar tais interesses e sugerir a realização de oficinas e outros. 
Mapa 1- Níveis de susceptibilidade à erosão por área de abrangência dos EDRs do Estado de SP.

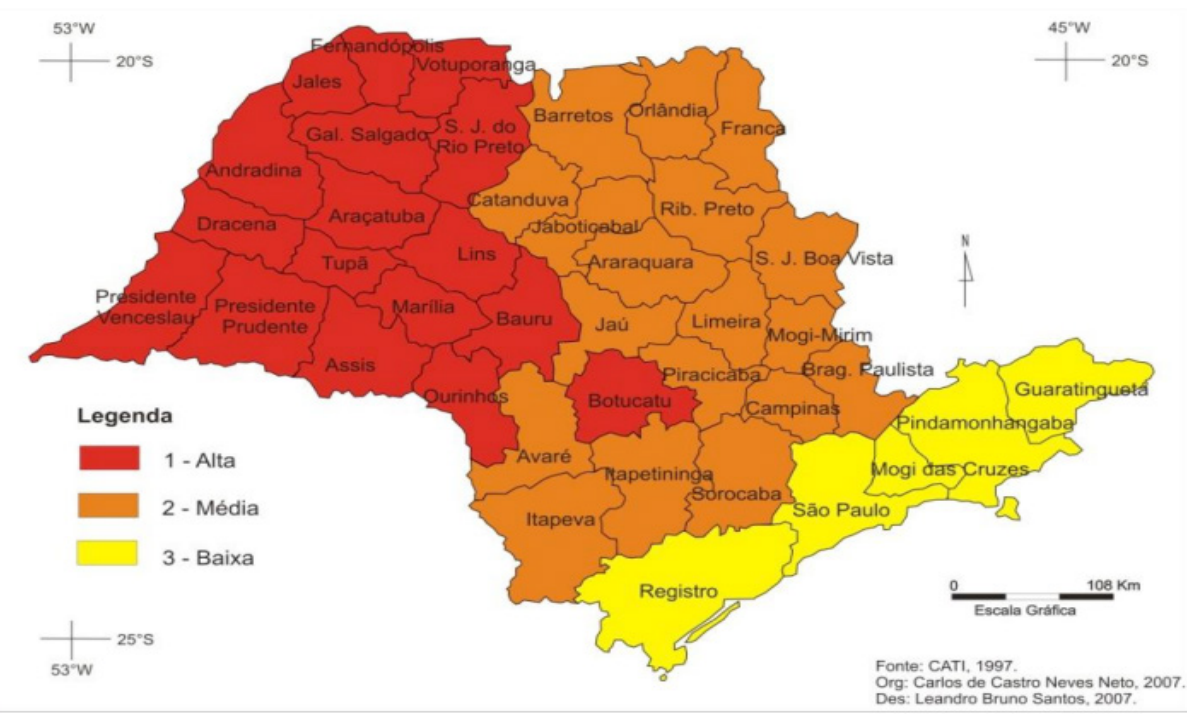

Fonte: Neves Neto, 2009.

Mapa 2 - Níveis de indigência por área de abrangência dos EDRs do Estado de São Paulo. Extraído de: Neves Neto, 2009.

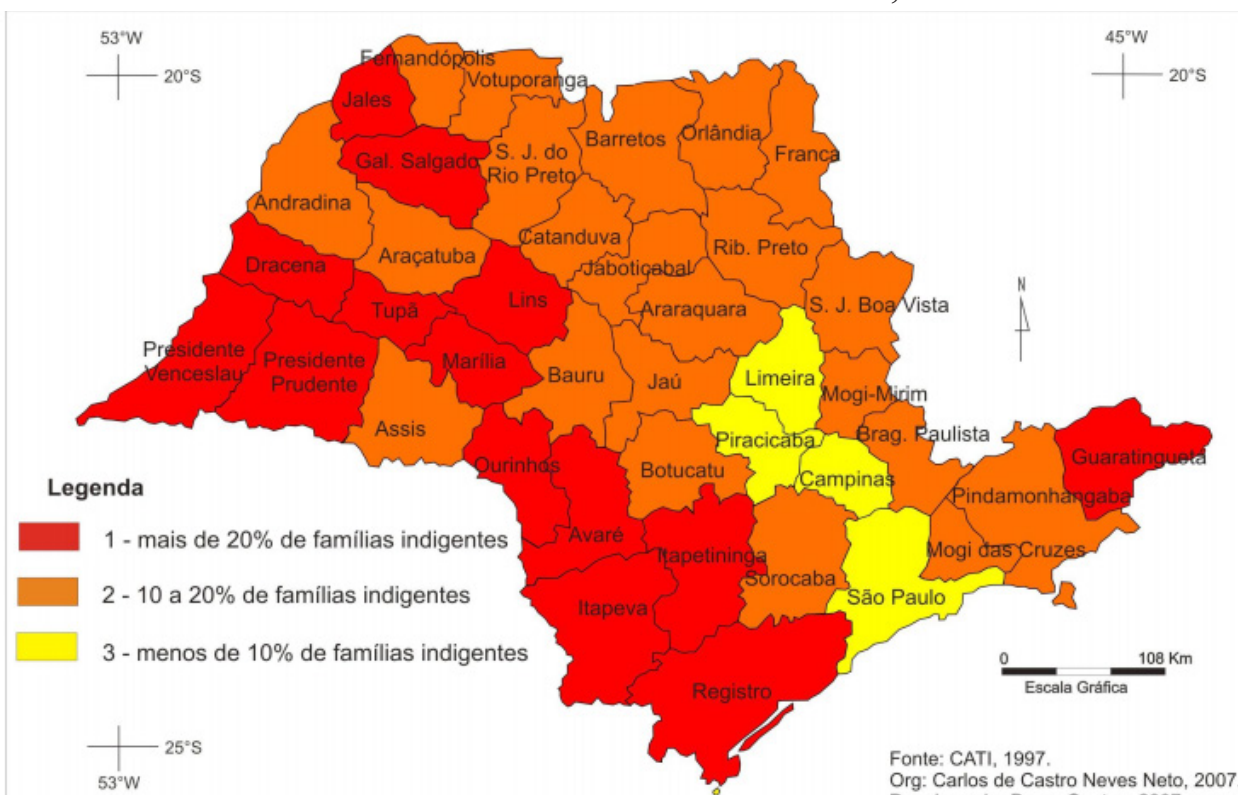

Fonte: Neves Neto, 2009.
Mapa 3 - Áreas prioritárias do PEMH. Extraído de: Neves Neto, 2009.

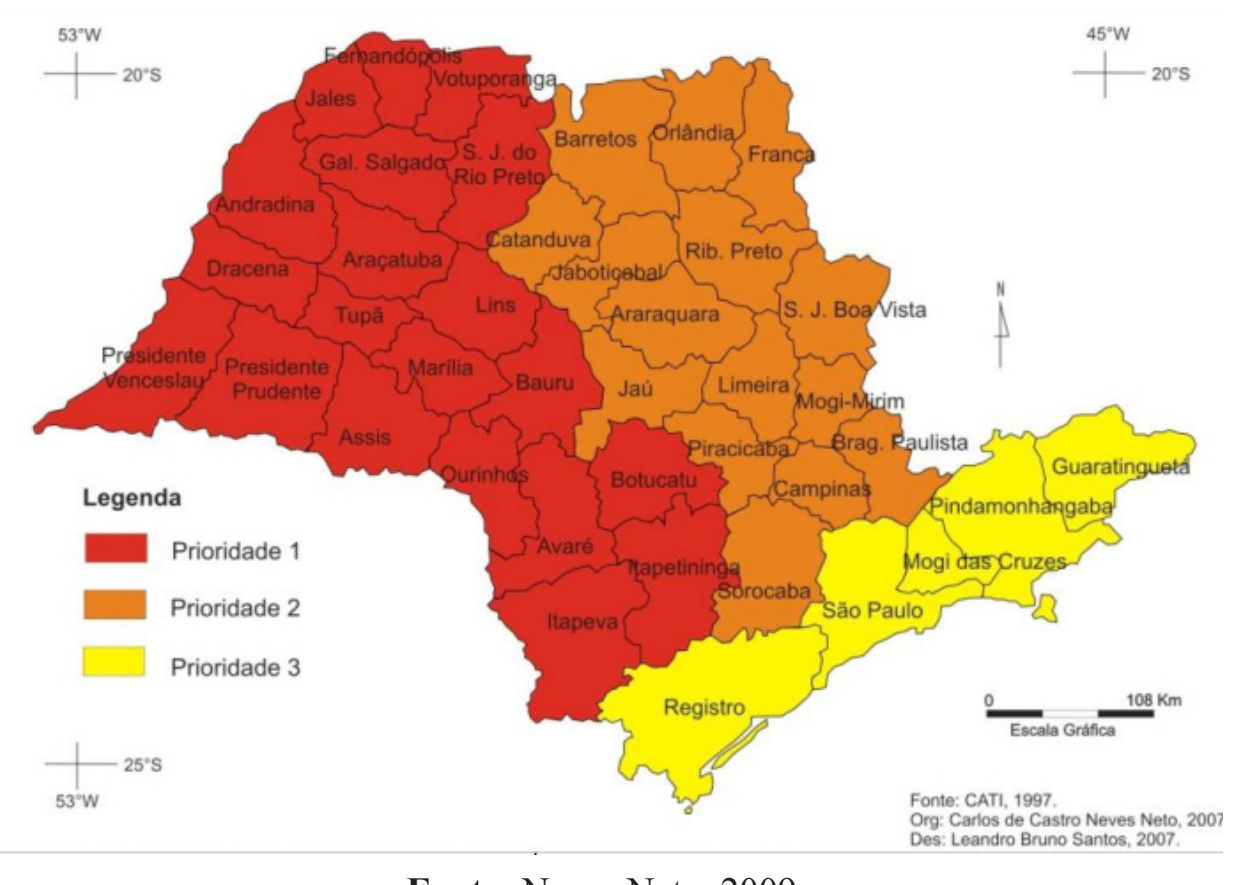

Fonte: Neves Neto, 2009.

As áreas de abrangência do programa foram divididas por EDRs (Escritório de Desenvolvimento Rural da CATI) e classificadas em três graus de prioridade. Os critérios para tal classificação foram a susceptibilidade à erosão do solo e a concentração da pobreza. Este segundo critério identifica os níveis de indigência pela concentração de famílias rurais com renda mensal inferior a dois salários mínimos (na época, o salário mínimo era de $\mathrm{R}$ \$ 415/mês), conforme o "Mapa da Fome" do IPEA (1993) e a "Conjuntura Alimentária" da Secretaria de Agricultura do Estado (WORLD BANK, 2009).

À área de prioridade 1 caberia $70 \%$ dos recursos oferecidos pelo PEMH. A área de prioridade 2 ficaria com $27 \%$ e a área de prioridade 3, com apenas $3 \%$ (NEVES NETO, 2009). Em todas as microbacias, os beneficiários preferenciais eram os pequenos produtores: aqueles com área total explorada de até 50 hectares, com $70 \%$ ou mais da renda familiar proveniente da agropecuária (incluindo neste percentual a aposentadoria rural), residentes na propriedade rural ou no município onde esta se localizava, ou em município vizinho (SÃO PAULO, 2005). Vale destacar, aqui, que um convênio firmado entre a Secretaria de Agricultura e a Fundação Instituto de Terras do Estado 
de São Paulo (Itesp) possibilitou que o PEMH fosse desenvolvido em alguns assentamentos rurais. O Itesp, vinculado à Secretaria Estadual da Justiça e da Defesa da Cidadania, é a entidade responsável por planejar e executar as políticas agrárias e fundiárias paulistas.

\section{A operacionalização do PEMH}

Após a formalização do empréstimo, procedeu-se à difusão de sua metodologia e objetivos junto à rede de extensionistas da CATI. A inserção da problemática ambiental e a nova forma de trabalho exigida pelo programa - não-setorial, participativo e por demanda - configuraram alguns de seus principais entraves iniciais, como mostram os relatos abaixo:

As regiões onde os técnicos foram mais permeáveis à idéia do programa, entenderam a necessidade do programa e começaram a trabalhar mais rapidamente, foram as regiões onde tivemos melhores resultados. Não foi homogêneo. [...] Mas principalmente na questão ambiental, nós temos uma questão que eu acho bastante séria. Os técnicos têm, nós temos, uma dificuldade muito grande de trabalhar com a questão ambiental. Hoje talvez seja até mais fácil, porque a questão ambiental é muito mais moda do que há 10 anos atrás. Então, existia uma certa resistência, dos técnicos inicialmente, e muitas vezes eles transferiam para os agricultores, diziam "não, os agricultores não querem saber disso". Esse foi o primeiro momento em que foi preciso romper muitas dessas resistências. (Gerente de Planejamento do PEMH)

Nós tivemos resistências, principalmente daqueles mais antigos ${ }^{8}$, que nunca tinham trabalhado com essa metodologia. Lógico, tudo que traz modificação traz insegurança. Os técnicos, eles tinham que acreditar no projeto, para depois estarem repassando. Imagina, se você não acredita no programa... É por isso que em algumas regionais, alguns lugares, o projeto não andou como em outras regionais, pelo problema do técnico não acreditar no trabalho. (Diretora técnica de EDR).

A pergunta passou a ser assim: por que que eu sou agrônomo? Porque

${ }^{8}$ Outra entrevistada, diretora de EDR, discorda deste ponto em específico, afirmando que a resistência vinha tanto dos extensionistas mais antigos da CATI quanto dos mais novos. ele [extensionista] virou um psicólogo, começou a discutir assuntos como a possibilidade de criar entretenimento para as mulheres ou para a criança acessar, além da escola, alguma outra atividade, ou criar um posto médico para o bairro. Então ele começou a virar um articulador. Ele começou a encaminhar demandas. Ele tentou imaginar como ele poderia contextualizar aquela situação. Então isso foi um crescimento. Tanto que você pode fazer uma pesquisa nas 40 regionais. Existe uma Cati antes do Microbacias, e uma Cati após o Microbacias. Não só na questão capacitação técnica, mas também na questão de execução de projeto, elaboração, solicitações de políticas públicas. Mudou o perfil da Coordenadoria. (Diretor administrativo de EDR).

Acho que o primeiro ano depois da assinatura ficou mais interno do que qualquer envolvimento, talvez, externo. Porque teve toda aquela preparação do pessoal, de mudar até o sistema, porque aí passou para um sistema mais participativo, que era, por exemplo, a construção do plano da microbacia. Era um novo modelo que começou a ser trabalhado [...] Até então, a gente era muito acostumado a desenvolver projetos sem o envolvimento dos agricultores [...]. Você não olhava a propriedade como um todo, a comunidade. Era um olhar isolado [...], de uma assistência técnica mais direcionada ao produto, por exemplo, produção de laranja. (Diretora técnica de EDR).

Em documento de avaliação do Microbacias I, a CATI confirma que o programa exigiu mudanças em sua filosofia de trabalho, antes centrada na assistência técnica tradicional, atendendo demandas técnicas pontuais dos produtores que procuravam a instituição, e depois passou a estender ao público rural conhecimentos sobre as atividades agropecuárias e a preocuparse com a qualidade de vida dos produtores. A instituição afirma que um dos principais impactos do programa foi o fortalecimento da rede de assistência técnica e extensão rural, com investimentos em infraestrutura, equipamentos e capacitação de técnicos, membros de conselhos municipais, dirigentes e membros de associações de produtores, agentes ambientais e professores (SÃO PAULO, 2009).

O Banco Mundial revela, em seu relatório final de avaliação do programa, uma visão mais crítica, afirmando que a estrutura e a capacidade da CATI no início eram inconsistentes com suas complexas responsabilidades. A falta 
de familiaridade com o Banco e com o ciclo do projeto, a necessidade de reorientar seu modelo de trabalho para acomodar mecanismos participatórios e descentralizados aplicados a uma área geográfica, e a necessidade de adaptar uma abordagem agronômica e ambiental tradicional para integrar preocupações sociais e sobre a pobreza causaram, na análise do Banco, sérios atrasos, inclusive criando problemas entre a instituição, a Secretaria de Agricultura e o Banco Mundial, e gerando exaustão e desilusão em uma parte sobrecarregada da equipe da CATI (WORLD BANK, 2009).

Em certo momento, segundo o Banco, considerou-se a possibilidade de contratar uma empresa privada para gerenciar/administrar o PEMH, ou contratar o Instituto Interamericano de Cooperação para a Agricultura (IICA) para formar uma estrutura administrativa paralela à CATI, mas nenhuma dessas opções atendia à proposta de modernizar e fortalecer a Coordenadoria enquanto agência promotora do desenvolvimento rural. A solução encontrada foi reforçar o time de consultores especializados contratados para trabalhar junto com a instituição. O Banco pondera suas críticas, na seqüência, afirmando que os desafios foram catalisadores do crescimento institucional da CATI, que acabou desenvolvendo tecnologias, métodos e parcerias cujos reflexos foram muito positivos para o saldo final do programa (WORLD BANK, 2009).

A "adesão" dos técnicos ao PEMH também esteve fortemente condicionada à desconfiança nas políticas públicas como um todo, em função de experiências negativas com projetos interrompidos e promessas não cumpridas, assim como o impacto, na agenda de prioridades política, de possíveis mudanças nos nomes de secretários ou coordenadores da CATI.

De repente o cara [técnico] vai lá, fala 'vamos fazer isso e aquilo', e aquilo não acontece... Para mim aqui é fácil, né, eu estou longe, não vou ter que dar explicação para ninguém. Mas para quem está na linha de frente lá é ruim, porque a cobrança vai estar o tempo todo em cima dele. Uma das coisas que os técnicos, eu acredito, iam querer ver para crer era se o programa ia ter continuidade, de fato. O que a gente pôde ver, e por isso é importante o financiamento externo, é que ele praticamente garante que você vai executar aquele projeto. Ele não fica ao sabor de mudanças políticas. Pelo menos foi assim com o PEMH. [...] A gente via nos outros estados, por exemplo, no Paraná, o pessoal dizia 'isso é uma vantagem muito grande, o governo muda e você tem continuidade'. Mas a gente [equipe de gerência do PEMH] também um pouco teve que ver para crer. (Gerente de Planejamento do PEMH).

Essa desconfiança na política também foi mencionada pelos entrevistados no tocante aos produtores rurais.

Você deixava desenhado o seu público, você oferecia o produto, e você não tinha a adesão ou a receptividade deles, mas não por falta de necessidade, e sim pela desconfiança que eles tinham nas políticas públicas existentes. Nós gastamos muito tempo com essa fase do projeto. [...] O problema é que, para o agricultor, por ele ser uma pessoa não inserida no mundo da informação, ele pega a televisão que fala que tem uma linha de crédito para ajudar o agricultor, mas ele não tem esclarecimento de quais os requisitos que ele precisa ter para acessar essa linha. Então, na verdade, o agricultor não tinha o acesso às políticas públicas de crédito. A assistência técnica rural passava por uma fase de adaptação, porque você saia de um assistencialismo para trabalhar com projetos participativos [...]. (Diretor administrativo de EDR).

A alternativa, enfatizada por todos os entrevistados desta pesquisa, foi trabalhar com um público estratégico para difundir informações e executar práticas que servissem como exemplo para os demais. Dentro do programa, havia uma classificação de três públicos distintos. O público estratégico era composto por presidentes de associação, presidentes de Conselho Municipal, diretores, gerentes de empresas ligadas ao setor rural, vereadores, prefeitos e lideranças. O público operacional era composto pelos executores e administradores do projeto. O público beneficiário eram os agricultores. A importância das demonstrações ou exemplos dos vizinhos nos remete à afirmação de Giddens (1991) de que a confiança do leigo tem um elemento pragmático baseado na experiência, além do seu conhecimento indutivo fraco.

Nós pegamos uma pessoa considerada estratégica, que tinha uma propriedade e era formador de opinião. Sentamos com essa pessoa, ele entendeu a dinâmica, o objetivo do projeto, recebeu o incentivo, e virou uma unidade de demonstração. [...] Ele chega na associação e fala: 'o projeto é sério, aconteceu comigo isso, isso e isso'. Assim existe um impacto no meio rural que nós [Cati] não causávamos, pelo 
problema dessa política pública desacreditada que nós tínhamos. (Diretor administrativo de EDR).

O entrevistado afirma que "na zona rural, todo bairro, sempre tem uma liderança", cujo perfil não se relaciona diretamente ao poder econômico ou ao tamanho da propriedade.

Mas existem algumas características que têm que ser analisadas. Onde você tinha uma comunidade que tinha por hábito a reunião religiosa, numa paróquia, numa igreja, para a festa do santo padroeiro, era muito mais fácil de você trabalhar, em relação a bairros que não tinham articulação nenhuma. Agora, o perfil do líder, cada lugar tem uma característica. Você pega Laranjal, é o cara que tem mais idade, porque lá existe esse traço da colonização italiana. Onde existe esse traço da questão religiosa envolvida, não a religião em si, mas o histórico, é mais fácil de você trabalhar. Então a liderança parte muito desse lado. Pratânia já é muito mais o caso da capacidade do empreendedor, de você ser uma pessoa que corre mais atrás. (Diretor administrativo de EDR).

Os entrevistados também atrelam o grau de adesão dos agricultores ao programa $^{9}$ às características pessoais dos técnicos. Estes atores são símbolos da perícia no meio rural, no entanto, os dados em campo indicam que aqueles que conseguem acessar outros recursos além do conhecimento especializado detêm mais chances de exercer poder. Esta pesquisa sugere a hipótese de que lógicas diferentes operam nos espaços de lugar, em oposição à crescente ${ }^{10}$ valorização dos sistemas peritos nos espaços de fluxos. Esta afirmação, porém, deve ser relativizada: quanto mais contato o agente mantém com o espaço de fluxos, mesmo que de modo descontínuo ou marginal, maior tende a ser a influência dos sistemas abstratos na reprodução do seu cotidiano. Assim, um produtor rural que mora na cidade, com fácil acesso a tecnologias da comunicação e da informação e elevado grau de instrução, possivelmente deposita mais confiança nas competências técnicas do que nas qualidades pessoais dos extensionistas.

\footnotetext{
${ }^{9} \mathrm{~A}$ maioria das análises feitas a respeito do programa considera positiva a receptividade do público beneficiário ao PEMH. Vide, por exemplo, Navarro (2008).

${ }^{10}$ Esta afirmação considera que o "desencantamento" da ciência e da tecnologia de que fala Beck (2010) implica não numa crítica absoluta à $\mathrm{C} \& \mathrm{~T}$, mas na possibilidade de florescimento de formas contestatórias de inovações, invenções e descobertas.
}

Você não pode avaliar uma pessoa para fazer um trabalho a nível de população rural pela qualificação técnica somente. Você tem que traçar o perfil da pessoa [técnico] para ter habilidade, para chegar na linguagem, para ganhar confiança, para estar inserido no meio deles. Porque se você não for aceita, ou se não tiver o respeito desses grupos, seu trabalho não evolui, por mais capacitado que você seja. (Diretor administrativo de EDR).

A recepção ao programa era muito boa. Num caderno, eu escrevia algumas coisas, mandava ele [o produtor] desenhar a propriedade dele, onde estavam as culturas. Até brincava: 'pô, você é um mau desenhista'. [...] Ali eu era obrigado a ter intimidade, se não eu não colocaria os meus objetivos em prática. Não é que eu forçava. Eu me moldava às características do produtor, procurava falar a linguagem dele. (Engenheiro agrônomo, extensionista da CATI).

Se eu chegar numa propriedade vestido como um engenheiro agrônomo, eu vou ser aceito. Se eu chegar de brinquinho e cabelo comprido, sem preconceito, o agricultor tem resistência. Mas porque é o tradicionalismo deles. Eles estão acostumados com o cara vestido daquele jeito, com cara séria. Então, isso tem influência. Agora a questão feminino ou masculino, não. Se você [a pesquisadora] for aceita lá, você vai conseguir qualquer tipo de informação. (Diretora técnica de EDR).

Esta última entrevistada menciona o exemplo de uma extensionista que é veterinária e é "muito querida" na região em que trabalha e de outra veterinária, da mesma EDR, que "não desperta simpatia" nos produtores rurais: "ela passa o serviço e os caras não fazem, não acreditam". Indagada quanto à aceitação do produtor rural às sugestões técnicas do extensionista em oposição às práticas mais tradicionais, a entrevistada responde: "Se ele confia no técnico, ele muda, mas se não, não. Se ele não confiar em você, ele vai ouvir tudo que você falou. Na hora que você for embora, ele deleta".

Goffman (2002) ajuda a interpretar esta fala. Para o autor, a informação a respeito do indivíduo serve para definir a situação, tornando os outros capazes de conhecer antecipadamente o que ele esperará deles e o que dele podem esperar. Assim informados, saberão qual a melhor maneira de agir para dele obter uma resposta desejada. O controle do corpo em situações 
de co-presença inclui modalidades perceptivas e comunicativas. De acordo com Giddens (1984), um encontro exige "exibição de presença" - aparência, vestuário, adorno, gestos -, calcada na consciência prática, ou seja, no conhecimento de regras e táticas mediante as quais a vida social é constituída e reconstituída através do tempo e do espaço. Com a intenção de ser visto como um agente capaz, produtor e extensionista monitoram reflexivamente a fala e a linguagem corporal ${ }^{11}$ própria, bem como a de seu interlocutor.

Desta forma, a percepção é organizada através de esquemas de previsão - o indivíduo prevê a nova informação que chega, ao mesmo tempo em que digere mentalmente a anterior. Este processo depende da continuidade espacial e temporal e tem como referência o corpo e seus envolvimentos com o mundo material e social. O sentido de confiança na continuidade do mundo objetivo e no tecido da atividade social depende, desta forma, de conexões especificáveis entre agentes individuais e contextos sociais (GIDDENS, 1984).

A confiança entre indivíduos em situações de co-presença e a confiança nos sistemas abstratos pode ser analisada não apenas pelas visitas dos técnicos às propriedades rurais. Diversas circunstâncias promovidas pelo PEMH geravam pontos de acesso ${ }^{12}$ aos sistemas abstratos: as reuniões para diagnóstico participativo e as reuniões dos Conselhos Municipais de Desenvolvimento Rural são fortes exemplos, já que o programa apostava no envolvimento ativo dos beneficiários.

Em consonância com as bandeiras da "participação"e da "descentralização" que ganharam espaço na época, a implantação das ações do PEMH dependia de uma série de procedimentos que envolviam ativamente beneficiários e a sociedade civil. A "participação" ocorria, por exemplo, na fase de escolha das microbacias a serem trabalhadas, uma vez que tal decisão era tomada pelos Conselhos Municipais de Desenvolvimento Rural (CMDR) - ressalva-se, porém, só participavam, de fato, aqueles atores envolvidos com os Conselhos.

Além disso, os Planos das Microbacias, documentos que continham os problemas e as estratégias para saná-los em determinada área, eram formulados após reuniões de diagnósticos participativos. Tais problemas diziam respeito à produção agropecuária e também à saúde (dificuldade de acesso a hospitais, má nutrição, etc.), educação (por exemplo, falta de escolas

\footnotetext{
A linguagem corporal é um discurso convencionalizado e normativo, assim como a fala. Não se distancia muito desta por também participar do caráter público da comunicação. Suas características triviais e espontâneas também são rigorosa e normativamente ordenadas (GIDDENS, 1984).

${ }^{12}$ Ponto de acesso é o terreno comum dos compromissos com rosto e sem rosto, ou seja, é o ponto de conexão entre leigos e os representantes dos sistemas abstratos (GIDDENS, 1984).
}

rurais), transporte (ausência ou má condição de ônibus escolar), segurança (roubos e violência), iluminação pública, dentre outros. As demandas que, levantadas, não fossem cobertas pelo PEMH deveriam ser encaminhadas para os órgãos competentes e, por isso, a realização de parcerias (com organizações não governamentais, empresas privadas e instituições públicas municipais, estaduais e federais) era estimulada.

Primeiro você tinha o Plano da Microbacia. Levava o técnico da Casa da Agricultura, procurava dividir o município no mapa, quais as possíveis microbacias, e em linhas gerais o número de produtores e a situação, a diversificação que tinha ali. Levava isso para o CMDR. Ai o Conselho, com base nos critérios do programa, fazia a pontuação e finalizava quais seriam as microbacias que iam ser trabalhadas, numa ordem de prioridades. Depois da seleção pelo Conselho, ai você começava a fazer a divulgação para os produtores. Agora uma coisa que ficou deste programa: a microbacia [seus produtores] não era consultada realmente se queria participar ou não. Porque depois que o Conselho selecionava, você já começava a trabalhar com a microbacia. [O agricultor só participava] enquanto membro do Conselho. [...] Depois de selecionado, fazia o levantamento socioeconômico, levantamento das unidades de produção, e aí fazia o Plano da Microbacia, de forma participativa. O diagnóstico já fazia parte do Plano. Você [o técnico] fazia o levantamento socioeconômico por meio de um questionário. Fazia o levantamento da unidade produtiva, que é um numero do sistema de produção mais frio. Daí fazia o levantamento socioeconômico e ambiental, onde via as questões ambientais, conservação do solo, recursos hídricos, gerenciamento da propriedade, se pertenciam a alguma organização... era um questionário mais completo. Com esses dados, você compilava e fazia para levar na reunião e mostrar para os agricultores. Então a gente falava, o maior problema citado aqui é esse ou aquele. Então a gente conversava e o pessoal ia construindo o plano. Daí o Plano é aprovado pelo Conselho e encaminhado para a Secretaria. Até o Plano ser aprovado, o esforço maior é da CATI. Agora, a execução do plano em si começa a partir do interesse dos produtores. (Diretora técnica de EDR).

Reunião só do microbacias [não tem a ver com Conselho], eu fazia lá na igrejinha. Primeira coisa que eu procurei saber é quando havia 
reza no município, e o compromisso de cada um a noite. Então eu já sabia, por exemplo, de sexta-feira tinha aquelas rezas lá. Eles são muito religiosos, devotos da igrejinha, animados pela Igreja. Então, nesse dia eu não fazia reunião, né, e não fazia em dia que tinha jogo de futebol muito bom, porque sabia que a coisa ia pegar fogo, não ia dar certo. Quase todo mês eu fazia uma reunião para a gente discutir o que nós podíamos fazer na microbacia. Porque para você formar um grupo de pessoas não é fácil. Tem muita desconfiança. Como eles já tinham confiança em mim, e eles sabiam que eu tinha endereço próprio dentro do município, que eu trabalhava na SAA, que isso pesa, o tipo de atenção que eu dava a cada família, eu procurava sempre resolver problemas, eles aceitaram a formação de grupos e compraram implementos agrícolas em conjunto. (Engenheiro agrônomo, extensionista da CATI).

Navarro (2008) defende que a "ação extensionista" tem centralidade decisiva no sucesso de projetos de microbacias e que, portanto, a formação técnica para o desempenho de tarefas tão complexas é mais do que necessária - embora esta formação, na avaliação do autor, não venha sendo "sequer remotamente" oferecida pelas universidades ${ }^{13}$. Para ele, os profissionais precisam ser capazes de propor técnicas inovadoras para os produtores e famílias rurais sobre a lógica sistêmica da ação extensionista em microbacias, o que exige conhecimento multidisciplinar. Os técnicos precisariam também ser capazes de mobilizar socialmente as famílias residentes (ou produtoras) nas microbacias trabalhadas, cooperar em sua organização social e, eventualmente, opinar no que Navarro chama de "delicadas questões políticas", que surgiriam quando as famílias rurais beneficiárias se sentissem fortalecidas o suficiente para estabelecer diálogos com outras forças municipais (a prefeitura, em especial), reivindicando outras ações externas aos projetos. Sua análise demonstra que o mecanismo mais saliente para "ativar" a participação das famílias rurais centra-se, sobretudo, na qualidade da ação extensionista realizada, particularmente se tal ação já tiver sido construída anteriormente em relações de confiança e outras atividades que produziram resultados (NAVARRO, 2008).

Os técnicos das Casas de Agricultura dos municípios têm papel de

\footnotetext{
${ }^{3}$ Tal fato é particularmente expressivo na área de Ciências Agrárias. Não se pode desconsiderar, entretanto, os esforços no sentido de incorporação das dimensões sociais e ambientais para além da esfera produtiva em algumas universidades brasileiras, em cursos de graduação e de pós-graduação, sobretudo aqueles ligados à Agroecologia e Agroecossistemas.
}

destaque no âmbito do programa não só por sua função de articulador, mas também porque o recebimento de subvenções econômicas e de doação de sementes e mudas, por parte dos produtores beneficiários, estava condicionado à aprovação do Projeto Individual da Propriedade (PIP). O PIP é o documento base para autorização das intervenções implementadas na propriedade; nele constam quais práticas devem ser adotadas na propriedade, quais equipamentos devem ser adquiridos e quais as recomendações técnicas previstas. Representa, assim, a materialização de um saber perito, que seguindo parâmetros estabelecidos em relações desencaixadas e nos espaços de fluxos, vai organizar, reproduzir ou transformar o espaço de vivência e trabalho do produtor rural, afetando sua experiência e seus laços cotidianos. A elaboração do PIP é responsabilidade do corpo técnico da CATI, o que ocorre, segundo a instituição, depois de um planejamento conjunto entre agricultor e técnico executor, levando em conta a capacidade de uso do solo, adequação à legislação ambiental e condições socioeconômicas do produtor (SÃO PAULO, 2009).

Eu chegava lá, tinha uma família. Ai eu começava a colocar em prática um questionário que a própria SAA tinha bolado. Lá tinha uma série de perguntas, tanto da parte social, como ele vivia, como ele fazia, as culturas que ele tinha, como ele explorava. E eu levava meu caderninho e ia pronto para bater um papo. Perguntava se ele podia ir comigo às divisas da propriedade, subia num trator ou ia a pé com ele, conversando. Eu tinha nessa altura que me disponibilizar para ele ser um grande amigo meu. Isso eu falava para eles todos. [...] Eu não podia levar mais problemas lá. Então eu chegava e não podia perguntar quais são os seus problemas, eu tinha que levar soluções. Então, eles me falavam: a água do espigão tá vindo pra cá, não pode. Eu já sabia que era terraceamento. Tecnicamente teria que desenvolver alguma coisa. (Engenheiro agrônomo, extensionista da CATI).

Embora ninguém possa optar por sair completamente dos sistemas abstratos, os leigos só conferem fidedignidade aos sistemas peritos após um cálculo de vantagens e riscos. Nos encontros regularizados, a confiabilidade está também associada à amizade e à intimidade (GIDDENS, 1991). Porém, os pontos de acesso lembram os leigos que "pessoas de carne e osso", potencialmente falíveis, são os operadores dos sistemas abstratos, de modo que a confiança - no sistema ou no indivíduo - deve sempre 
ser renovada. Isso explica em parte porque os PIP's são, muitas vezes, elaborados, mas não colocados em prática. No caso da extensão rural, em específico, deve-se atentar para um processo de sucateamento das agências públicas prestadoras desses serviços, frequentemente culminando com a deslegitimação das instituições e dos próprios técnicos; esses, na iminência de terem seus espaços ocupados por empresas privadas de prestação de serviços, apostam na construção imediata de laços de confiança como uma estratégia prática para contornar tal fragilidade institucional. A dificuldade na sustentação política dos serviços públicos de extensão rural se agrava com a gradativa formação de uma imagem negativa dessas organizações, baseada em diagnósticos que as apresentavam como autoritárias, dispendiosas, despreocupadas com a racionalização dos custos-benefícios, operadas por extensionistas pouco motivados, mal treinados e pouco competentes, com abordagens inadequadas e pacotes técnicos antieconômicos, passando-se a questionar o papel de tais agências nos processos de desenvolvimento agrícola (DIESEL et al., 2008). A ausência de reflexão nesse sentido leva, muitas vezes, à simplificação da questão como um "desinteresse" por parte do produtor rural:

Muitas vezes, temos microbacias que todos os agricultores tiveram PIPs, mas poucos se concretizaram. Acho que o agricultor, na hora de realmente colocar aquilo em prática, não tem interesse. É nessa hora que eu falo que o envolvimento do técnico tem que ser muito grande naquela comunidade em que ele atua, com os produtores. Para se conseguir avançar nessas questões. E esse técnico tem que ter habilidade no trabalho de extensão rural. Se ele for muito só voltado ao sistema produtivo, ele não consegue concretizar aquele PIP com o produtor. (Diretora técnica de EDR).

$\mathrm{Na}$ prática, o produtor individual ou o grupo de produtores deveriam arcar com os custos da ação a ser implementada na propriedade rural (ex: abastecedouros comunitários, equipamentos para plantio direto, calcário, cercas para proteção de mananciais, aquisição de tratores, fossa asséptica biodigestora, mudas florestais, etc). Depois de finalizada a ação, esta deveria ser fiscalizada para que, em seguida, o produtor ou o grupo fossem ressarcidos pelo PEMH em até $90 \%$ do gasto total, dependendo do tipo de prática implementada e do tamanho do produtor rural. A contrapartida do produtor rural é justificada como modo de assegurar seu comprometimento para com o programa, bem como para evitar que tal política tivesse um caráter assistencialista. A fiscalização da aplicação dos recursos dos incentivos do Programa ocorria através do acompanhamento por parte dos extensionistas e da Gerência Regional, do controle social realizado pelos Conselhos Municipais e associações de produtores, além de auditorias externas e do Banco Mundial (SÃO PAULO, 2009b).

A despeito do que muitos entrevistados chamaram de "estrutura engessada" do programa, em referência às regras e aos procedimentos roteirizados que deviam ser seguidos, os atores também negociavam suas estratégias de atuação de acordo com seus interesses. E essas estratégias poderiam ser uma simples acomodação ao PEMH, como no primeiro exemplo abaixo, ou poderiam representar uma ruptura frente às obrigações assumidas, como na segunda fala.

Para você ter uma idéia, eles tinham uma definição que agricultor familiar tinha que ter, no máximo, dois empregados fixos. Nós tivemos um caso que o senhor trabalha com fruticultura $\mathrm{e}$ fruticultura demanda muita mão-de-obra. E ele é familiar, ele vive da propriedade. Ele se encaixava em tudo, só que aí ele saia pelo número de funcionários fixos. Ele acabou participando, só que não acessou o crédito individual, entrou só no coletivo. (Diretor administrativo de EDR).

Isso eu acabei aprendendo sabe como? Eu fiz o primeiro grupo de roçadeira ecológica. Nem todos tinham o mesmo dinheiro no mesmo dia. E isso acabou dando problema. Quando eu fui comprar a madeira, algumas outras coisas, eu falava para os caras: eu compro, eu quero o último preço de vocês à vista. Vou abrir uma concorrência e quero tudo em envelope fechado. Só que eu vou falar uma coisa: o a vista de vocês vai ter que ser dividido em três ou quatro vezes, tá?! Eu falava: você não pode me comprometer, tá. Eu só recebo esse material, eu só recebo a nota. Você pega uma nota promissória com a assinatura dos agricultores envolvidos, porque eu não quero correr atrás de gente que não pagou. E eles [agricultores] morrem de medo de ficar com o nome sujo. O modo como eu fiz funcionou e ajudou os produtores. Ficou muito bom. Eu fiz isso com todas as atividades. (Engenheiro agrônomo, extensionista da CATI)

A fala acima se refere à exigência, por parte do Banco Mundial, de que 
os pagamentos relativos às práticas implementadas nas propriedades rurais ou a compra de equipamentos e materiais fossem efetuados à vista, pelos produtores, para posteriormente serem reembolsados pelo programa. Em todas as entrevistas feitas, técnicos e diretores de EDR demonstravam conhecer este procedimento de emissão da nota fiscal à vista e concomitante pagamento parcelado, sem, contudo, se comprometer com a negociação.

Essa sensibilidade, todos, em todas as regiões, tiveram. E as próprias empresas acabavam entendendo o processo e acabavam negociando com os produtores. Mas não estava em nenhum papel, né. Foi a forma de poder viabilizar, porque muitas vezes é pequeno produtor, e não tem dinheiro suficiente para dispor naquele momento e aguardar três meses até o reembolso. Então tinha essa sensibilidade, o que eles negociavam com a empresa era problema deles. (Diretora técnica de EDR).

A Avaliação de Meio Termo ${ }^{14}$ do programa, realizada em 2004 por uma empresa de consultoria externa, detectou que o PEMH se desenvolvia de modo mais lento que o planejado, indicando algumas limitações do programa. Tal fato levou o Banco Mundial a cancelar US\$ 10 milhões do orçamento e a estender o prazo final em dois anos, de 2006 para 2008 (WORLD BANK, 2009). Por este motivo, o Banco reduziu as metas quantitativas do PEHM.

Após a revisão que sucedeu à Avaliação de Meio-Termo, o Banco intensificou sua intervenção no desenvolvimento do programa. A dominação através dos espaços de fluxos pode também ser sugerida através do discurso do Banco Mundial que relaciona os resultados positivos do programa à esta forte intervenção, nos últimos anos do Microbacias I. Nas palavras do Banco:

Duas intervenções fizeram grande diferença para os resultados do projeto: (a) o alto nível de interferência por parte dos gerentes do Banco, depois da Avaliação de Meio Termo, quando o desempenho geral continuava fraco e levantava a possibilidade de cancelamento, estabeleceu disciplina e condições realistas para uma forte melhora na performance e maior uso do montante aprovado para o empréstimo (já reduzido); e (b) a extensão de dois anos no prazo de enceramento. Os gerentes do Banco se encontraram com líderes e autoridades do Estado para explicar o projeto, revisar e resolver problemas críticos que afetavam o desempenho - especialmente

${ }^{14}$ DEL GIUDICE ASSESSORIA TÉCNICA LTDA. PEMBH - Avaliação de Meio Termo: Relatório Final. Belo Horizonte, setembro de 2004 as compras - e estabelecer um plano de ação e um calendário para a conclusão do projeto. A produtividade e o sucesso dos dois anos estendidos ressaltaram o potencial inerente à correta avaliação da situação no campo, à aferição das condições mínimas para se fazer um trabalho de extensão, à promoção do suporte ao emprestador para um plano de ação bem desenhado e à supervisão rigorosa de sua implementação. (WORLD BANK, 2009, p. 11, tradução nossa)

Em seu relatório final de avaliação do programa, o Banco também afirma que o Microbacias só ganhou força depois de algumas mudanças na equipe de alto escalão do governo e dos esforços mais intensivos feitos pelo Banco para explicar os princípios e justificativas do projeto aos membros novos do governo (WORLD BANK, 2009). O discurso sugere que o Banco acredita que sua capacidade técnico-administrativa - a qual carrega a lógica interna da instituição - foi imprescindível para o que o programa atingisse algum sucesso em seu desenvolvimento. Os códigos embutidos neste jogo de forças pertencem à estrutura social e transitam pelos nós das redes na forma de fluxos, de modo que a dominação decorrente disso não seja explicitamente marcada como tal - uma característica da sociedade informacional.

Dados oficiais informam que 518 municípios estabeleceram parceria com o Governo do Estado para implantação do PEMH, 966 planos de microbacias foram aprovados, representando 3,3 milhões de hectares trabalhados e o envolvimento de 70.000 famílias de agricultores nas ações do Programa (SÃO PAULO, 2009). Esses números estão abaixo das metas iniciais traçadas pelo PEMH, mas superam as metas revisadas após a Avaliação de Meio-Termo. Mais do que a magnitude estatística, os dados nos induzem a refletir sobre a citação de Giddens (1991): "Em condições de modernidade, uma quantidade cada vez maior de pessoas vive em circunstâncias nas quais instituições desencaixadas, ligando práticas locais a relações sociais globalizadas, organizam os aspectos principais da vida cotidiana".

\section{Considerações finais}

Nos últimos 20 anos, sistemas peritos gestaram novas propostas teóriconormativas para o desenvolvimento rural, com base na observação das transformações das dinâmicas socioculturais, econômicas e ambientais experimentadas no meio rural. Estas reflexões influenciaram a concepção de políticas públicas territorializadas, de caráter descentralizado e participativo, 
com vistas à melhoria da qualidade de vida da população do campo, como é o caso do Programa de Microbacias do Estado de São Paulo, estudado neste trabalho.

Os resultados da pesquisa revelam que a operacionalização de políticas públicas participativas e descentralizadas em territórios rurais exige um ativo papel dos profissionais da extensão rural (agrônomos, zootecnistas e veterinários). Destes peritos se espera uma postura de articulador e catalisador de interesses, de modo a promover a mobilização de capitais sobretudo sociais - que favoreçam o desenvolvimento das potencialidades locais. A atuação profissional destes peritos precisa se adaptar aos novos contornos das dinâmicas rurais, que adquirem complexidade com a incorporação de elementos ambientais e sociais ao que antes se atrelava simplificadamente a uma questão de reprodução econômica - a atividade agropecuária. Neste sentido, identificamos em campo alguns aspectos das disputas pela construção de significados para o "novo rural", da mesma forma que percebemos os conflitos em torno da reformulação de identidades por parte dos atores envolvidos.

O estudo também conclui que, embora a atuação dos especialistas esteja ancorada em conhecimentos peritos, estes não são suficientes para garantir a adesão, às políticas públicas de desenvolvimento rural, de agentes que carregam racionalidades distintas. Em nossa leitura, isso sugere que os sistemas peritos desfrutam de mais legitimidade entre os atores sociais que estão mais próximos dos espaços de fluxos, onde circulam dados e informações classificadas e hierarquizadas pela perícia, mesmo que de modo descontínuo e parcial.

Outro ponto a se destacar é a questão da confiança, dirigida não aos sistemas abstratos, como teoriza Giddens, mas sim às características pessoais dos peritos. Em nossa avaliação, o bom andamento do PEMH em algumas microbacias e seu fraco desempenho em outras está atrelado, no mais das vezes, à simpatia, à cordialidade, aos laços de amizade entre técnicos e produtores, e não à competência técnica dos primeiros. Cabe observar, ainda, que os laços estabelecidos com base na pessoalidade não podem ser construídos na execução de um único programa, mas dependem de um histórico de interação institucional, do desenvolvimento paralelo de outros programas e políticas públicas, enfim, de um contexto não imediato de relações sociais.

\section{Referências Bibliográficas}

ABRAMOVAY, R. O capital social dos territórios: repensando o desenvolvimento rural. Economia Aplicada. n ${ }^{\circ}$, vol. IV: 379-397, abril/ junho 2000 .

DIESEL, Vivien et al . Privatização dos serviços de extensão rural: uma discussão (des)necessária?. Rev. Econ. Sociol. Rural, Brasília , v.46, n.4, p. 1155-1188, dez 2008. Disponível em: <http://www.scielo.br/scielo. php?script=sci_arttext\&pid=S0103-20032008000400010\&lng=en\&nrm= iso>. Acesso em 08 jun 2017.

GAMEIRO, M. B. P. Além do financiamento: uma análise das propostas do Banco Mundial para o desenvolvimento rural. In: Anais do I Seminário Internacional Ruralidades Trabalho e Meio Ambiente. São Carlos, UFSCAR, 2011. CD-Rom.

GEHLEN, I. Políticas públicas e desenvolvimento social rural. São Paulo em Perspectiva, v. 18, n. 2, p. 95-103, 2004.

GIDDENS, A. A constituição da sociedade. Trad. Álvaro Cabral. São Paulo: Martins Fontes, 1989.

GIDDENS, A. As conseqüências da modernidade. Trad. Raul Fiker. São Paulo: Editora Unesp, 1991.

GIDDENS, A. Modernidade e Identidade. Rio de Janeiro: Jorge Zahar Ed, 2002.

GRAZIANO DA SILVA, J. A nova dinâmica da agricultura brasileira. 2 ed. rev. Campinas: Unicamp, 1998. 211 p.

MARTINS, R. C. Ruralidade e regulação ambiental: notas para um debate político-institucional. Revista de Economia e Sociologia Rural, v. 43, p. 249-266, 2005.

MOREIRA, R. J. Assimetrias de poder, cultura, territórios ecossistêmicos 
e globalizações. In: Lima, E. N.; Delgado, N. G.; Moreira, R. J. (Org.). Mundo Rural IV - configurações rural-urbanas: poderes e políticas. Rio de Janeiro: Mauad Editora, 2007.

NAVARRO, Z. Manejo de recursos naturais ou desenvolvimento rural? O aprendizado dos "projetos microbacias" em Santa Catarina e São Paulo. Relatório de pesquisa. São Paulo, 2008.

NEVES NETO, C. C. O Programa Estadual de Microbacias Hidrográficas em São Paulo: o caso do município de Assis/SP. Presidente Prudente, 2009. 196 f. Dissertação (mestrado). Programa de Pós-Graduação em Geografia, Faculdade de Ciências e Tecnologia, Universidade Estadual Paulista.

PLOEG et al. Rural Development: from practices and policies towards theory. Sociologia Ruralis, Netherlands, 40 (4): 391-407, 2000.

SÃO PAULO (Estado). Secretaria de Agricultura e Abastecimento - Coordenadoria de Assistência Técnica Integral. Retratos de uma transformação ambiental, econômica e social - Ações desenvolvidas pelo Programa Estadual de Microbacias Hidrográficas, 2000-2008. Imprensa Oficial do Estado de São Paulo. Campinas, 2009.

SÃO PAULO (Estado). Secretaria de Agricultura e Abastecimento - Coordenadoria de Assistência Técnica Integral. Informe final de implementação do Programa Estadual de Microbacias Hidrográficas - PEMH (ICR) (BIRD-42380). Campinas, 2009 b.

WOODS, M. Developing Europe's rural regions in the era of globalisation (DERREG) - An interpretative model for better anticipating and responding to challenges for regional development in an evolving international context. Aberystwyth University, 2009. Disponível em: < http://www.derreg.eu/system/files/D5.1\%20DERREG\%20Conceptual\%20 Framework.pdf>. Acesso em 15 out. 2010.

WORLD BANK. Implementation completion and results report (IBRD42380). Washington, June 1, 2009. Disponível em: $<\underline{\text { http://go.worldbank. }}$ org/7FHWDNIHC0>. Acesso em 02 maio 2010. 